\title{
Enhanced ductility in harmonic structure designed SUS316L produced by high energy ball milling and hot isostatic sintering
}

Ruixiao Zheng ${ }^{\mathrm{b}, \mathrm{c}}$, Zhe Zhang ${ }^{\mathrm{a}, \mathrm{c} *}$, Masashi Nakatani ${ }^{\mathrm{c}}$, Mie Ota ${ }^{\mathrm{c}}, \mathrm{Xu} \mathrm{Chen}^{\mathrm{a}}$, Chaoli Ma ${ }^{\mathrm{b}}$, Kei Ameyama

${ }^{\text {a }}$ School of Chemical Engineering and Technology, Tianjin University, Tianjin 300072, PR China

${ }^{\mathrm{b}}$ Key Laboratory of Aerospace Advanced Materials and Performance of Ministry of Education, School of Material Science and Engineering, Beihang University, Beijing 100191, China

${ }^{c}$ Department of Mechanical Engineering, Faculty of Science and Engineering, Ritsumeikan University, 1-1-1 Noji-higashi, Kusatsu, Shiga 525-8577, Japan

*Corresponding author: Tel: +86-15122119030; Email: zhe.zhang@ @ju.edu.cn

\begin{abstract}
The objective of the present study is to optimize the mechanical properties of commercial SUS316L stainless steel through harmonic structure design. The harmonic structured SUS316L compacts were fabricated by a process including high energy ball milling and subsequent hot isostatic pressing. Although the harmonic structured compacts had a bimodal grain size distribution, our investigations showed that both hardness and yield strength still well resembled the Hall-Petch relationship. A great combination of high yield strength and improved uniform elongation can be achieved simultaneously in the harmonic structured SUS316L compacts $\left(\sigma_{\mathrm{y}}=695 \mathrm{MPa}, \varepsilon_{\mathrm{u}}=27.1 \%\right)$. The improved ductility was attributed to both the strain hardening induced by the coarse-grained structure and the extra strain hardening caused by the peculiar
\end{abstract}


macroscopic network of ultrafine-grained structure. It was suggested that core grain size of approximately $1.2 \mu \mathrm{m}$ and shell volume fraction of approximately $50 \%-60 \%$ were the optimized harmonic structure design for austenite stainless steel.

Keywords: Stainless steel; Ultrafine grains; Harmonic structure design; Strength; Mechanical milling; 


\section{Introduction}

Owing to the excellent corrosion resistance, oxidation resistance and good formability, SUS316L stainless steel has been widely used as engineering material in automotive components, high pressure vessels and medical devices [1-5]. However, further application of this material is hindered by its relatively low tensile strength. Grain refinement has been used extensively to produce high strength materials [6-10]. The extremely high yield strength and hardness have been achieved in the ultrafine-grained (UFG) or nanograined (NG) SUS316L stainless steels synthesized by several thermo-mechanical methods, such as surface mechanical attrition treatment (SMAT) [1, 2], equal channel angular pressing (ECAP) [11], high pressure torsion (HPT) [12] and thermal cycling [13-15]. The relationship between grain size and mechanical properties has been investigated in the homogeneous grain-structured SUS316L stainless steels, wherein the yield strength well resembled the Hall-Petch relationship $[1,14]$. However, due to the early appearance of plastic instability, ductility tends to be deteriorated in the UFG or NG SUS316L steels [11-15]. Therefore, it is imperative to achieve a good combination of high strength and high ductility in the UFG or NG SUS316L steels for their practical applications.

It is well-known that the bimodal grain size distribution is a simple way in realizing high strength and reasonable ductility. Strength can be influenced by ultrafine grains and ductility can be prompted by coarse grains (CG) simultaneously [16-22]. In recent years, the microstructure design based on multiple scales and multiple layers has been proposed to improve the mechanical properties of metallic materials. "Gradient nanograined structure" has been synthesized successfully in IF steel and $\mathrm{Cu}$, and these metals exhibited extremely large ductility, which was attributed to an extra strain hardening caused by a macroscopic strain gradient [23, 24]. "Trimodal 
structure", consisting of NG or UFG, CG, and ceramic particles, was realized in aluminum based composites. Such structure topology can provide improved mechanical properties and crack propagation resistance [25].

"Harmonic structure", consisting of a coarse-grained structure ("core") and a three-dimensional continuously connected network of ultrafine-grained structure ("shell"), has been proposed by Ameyama [26] and others [27-39]. Commonly, the distribution of CG and UFG is random in the traditional bimodal structure, which may tend to induce strain localization. By contrast, according to the experiments and simulation of harmonic structure, the peculiar macroscopic network structure can restrict the strain localization effectively during plastic deformation, which results in an extra strain hardening $[28,29,35]$. A variety of harmonic structure designed materials, such as stainless steel [26-31], pure Ti [32, 33], Ti-6Al-4V [34, 35], $\mathrm{Cu}[36,37]$ and Co-Cr-Mo [38, 39], demonstrated a good combination of high strength and large elongation, especially large uniform elongation.

The appropriate grain size and volume fraction for the design of the bimodal structured materials with high strength and high ductility have been investigated [40-44]. Hono et al. [42] reported that bimodal grain size distribution with nanocrystalline grains of $80 \mathrm{~nm}$ and coarse grains of nearly $1 \mu \mathrm{m}$ in a ferrite solid solution demonstrated high compressive yield strength and large plasticity. Moreover, the appropriate volume fraction of the nanocrystalline grains for the bimodal structured Fe is approximately $60-65 \%$ [40]. A similar tendency was also reported in a bimodal structured Al/Mg alloy by Han et al. [43]. However, the desirable volume fraction of the ultrafine grains for the bimodal structured pure $\mathrm{Ti}$ is approximately $85 \%$ [44]. In the previous studies, the exact grain size and volume fraction of CG and UFG are quite different in the 
harmonic structured materials. The outcome properties of the harmonic structured materials span a relatively wide range. So far, the optimized grain size and volume fraction of CG and UFG for harmonic structure designed materials have not been revealed yet.

In the previous studies [26-39], a planetary ball mill was applied to synthesize the bimodal structured powders before sintering. However, the grinding action will stop if the centrifugal force acting on the steel balls exceeds the force of gravity at a certain speed. So it was difficult to introduce very high energy to the powders by planetary ball mill. By contrast, horizontal ball mill has a horizontal shaft with a series of impellers inside container, which can rotate at high speed. Moreover, grinding action can occur between balls, between balls and container, and between balls, shaft, and impellers [45]. The horizontal ball mill can generate much higher energy than the planetary ball mill.

Powder metallurgy method can greatly reduce the amount of used metals compared to other metal removal processes, thereby reducing yield losses in manufacture and often resulting in lower costs. The harmonic structure designed stainless steel has high application value and development potential in medical industry. Therefore, the objective of the present study is to fabricate the harmonic structured SUS316L compacts by high energy ball milling and subsequent hot isostatic sintering process. Then, investigate their microstructure evolution and mechanical properties. Finally, try to reveal the appropriate microstructural characteristics, i.e. grain size and volume fraction of CG and UFG, for the harmonic structure designed austenitic stainless steel through analyzing the relationship between microstructure and mechanical properties.

\section{Experiment}


Commercial gas-atomized SUS316L powders were provided by Fukuda Metal Foil \& Powder Co., Ltd. The powder particle size ranges from approximately $1 \mu \mathrm{m}$ to $20 \mu \mathrm{m}$, and the chemical composition is shown in Table 1, which corresponds to the Japanese Industrial Standard (JIS G 4303: 2012). Firstly, initial powders were mechanical milled by a horizontal ball mill (Zoz Simoloyer CM01) under argon gas atmosphere at room temperature. SUS304L balls $(5 \mathrm{~mm}$ diameter) and container were used, and the ball-to-powder weight ratio was 8:1. The mechanical milling was carried out for 36ks, 108ks and 180ks at a constant speed of $1000 \mathrm{rpm}$, respectively. Then, the milled powders were charged into a mild steel capsule and sintered by hot isostatic pressing (HIP) with a pressure of $200 \mathrm{MPa}$ for $14.4 \mathrm{ks}$ at $1173 \mathrm{~K}$. The symbols IP, MM36ks, MM108ks, and MM180ks mean that the compacts sintered from the powders milled for $0 \mathrm{ks}, 36$ ks, $108 \mathrm{ks}$, and $180 \mathrm{ks}$, respectively.

Microstructure was observed by an electron backscattering diffraction (EBSD) system (FEI (Philips) Siron) operated at $15 \mathrm{kV}$. Grain size, high-angle grain boundaries (HAGBs) and low-angle grain boundaries (LAGBs) were mapped. The diameter of grains and area fraction of the "core" and "shell" regions were defined as grain size and volume fraction by calculating from images.

In order to study the Hall-Petch relationship in the harmonic structured SUS316L steels, the average grain size $\left(\mathrm{d}_{\mathrm{A}}\right)$ of the entire microstructure is determined by an area (volume) fraction-the inverse grain sizes in the two regions, i.e. $d_{A}{ }^{-1}=d_{\text {shell }}{ }^{-1} \times S_{f}+d_{\text {core }}{ }^{-1} \times\left(1-S_{f}\right)$. Where $S_{f}$ is the volume fraction of the ultrafine-grained structure (shell), $d_{\text {shell }}$ and $d_{\text {core }}$ are the average grain size of ultrafine grains and coarse grains, respectively. The mentioned method has been applied in many papers to discuss the effects of grain size on mechanical properties of bimodal structured materials 
$[40,46]$.

Mechanical properties, such as hardness, strength and elongation, were evaluated. The Vickers hardness was measured under a load of $0.98 \mathrm{~N}$. The tensile specimens had a gauge length, width and thickness of $3 \mathrm{~mm}, 1 \mathrm{~mm}$ and $1 \mathrm{~mm}$, respectively. Tensile tests were carried out on a universal testing machine under displacement control with a nominal strain rate of $5.56 \times 10^{-4} / \mathrm{s}$ (cross-head speed of $0.1 \mathrm{~mm} / \mathrm{min}$ ). The displacement of gauge area was recorded by a non-contact CCD camera system. At least four specimens were tested for each specimen condition, and the obtained results were reproducible.

\section{Results and discussion}

\subsection{Microstructural characteristics of the harmonic structured SUS316L compacts}

The morphology of initial powders and milled powders is shown in Fig.1. As shown in Fig.1a, the particle size of gas-atomized initial powders was irregular owing to the rapid cooling. The flake-shape powders were produced after mechanical milling for $36 \mathrm{ks}$ and $108 \mathrm{ks}$ (see Fig.1b and 1c). By contrast, the milled powders were agglomerated owing to cold-welding between the powder particles as the milling time increased to $180 \mathrm{ks}$ (see Fig. 1d).

Figure 2 shows the microstructure of SUS316L stainless steels produced from various preparation methods. Fig.2a-2e are grain boundary maps, wherein HAGBs and LAGBs are drawn by blue lines and green lines, respectively. Fig. $2 \mathrm{f}-2 \mathrm{j}$ are grain distribution maps, wherein the aqua blue area indicates the grain size is over than $1 \mu \mathrm{m}$, while the orange area means the grain size is less than $1 \mu \mathrm{m}$. As shown in Fig.2a and 2f, the common SUS316L bulk has a homogeneous CG microstructure with an average grain size of $15.6 \mu \mathrm{m}$. 
It can be observed from Fig. $2 \mathrm{~b}$ and $2 \mathrm{~g}$ that a bimodal structure composed of coarse grains and ultrafine grains is formed in IP compact owing to the irregular particle size of initial powders. The coarse grains are surrounded by ultrafine grains. By contrast, an increase of milling time leads to a decreased grain size and an increased volume fraction of ultrafine grains (Fig.2c-e and Fig.2h-j). Moreover, as shown in Fig. $2 \mathrm{~h}-2 \mathrm{j}$, it is notable that the clear connected network of ultrafine-grained structure can be observed. Namely, due to the wide distribution of particle size of initial powders, a partially harmonic structure is formed in the sintered compact without milling. Furthermore, the clear harmonic structure can be obtained in the sintered compacts prepared from milled powders.

The XRD results of the milled powders and sintered compacts are shown in Fig. 3. As shown in Fig.3a, both FCC and BCC structure can be observed in the initial powders. It is thought that the initial powders have both austenite phase and ferrite phase, which may be related to the rapid cooling during the atomization. By contrast, the peak of BCC structure increases gradually as milling time increasing, which indicates that the amount of ferrite phase in the vicinity of the milled powders surface increases gradually. It was reported that the nano ferrite grain structure can be formed in SUS316L powders by the milling process, which is referred to as a strain-induced-ferrite transformation [47]. However, it can be seen from Fig. 3b that both IP compact and the compact prepared from milled powders have FCC structure only, which indicates that all of ferrite phase transfers to austenite phase during sintering process.

Figure 4 and Table 2 present the variation of grain size and UFG volume fraction in the sintered compacts. The average grain size of the core in IP compact is approximately $4.0 \mu \mathrm{m}$, while the shell has an average grain size of approximately $1.5 \mu \mathrm{m}$. It can be noted that the average grain size in the core decreases gradually as the milling time increases. While, mechanical milling leads to a 
minor change of grain size in the shell, and the grain size ranges from $0.2 \mu \mathrm{m}$ to $1.0 \mu \mathrm{m}$. The shell fraction increases monotonically from $26.5 \%$ to $73 \%$.

Figure 5 shows the variation of the average grain size $\left(d_{A}\right)$ in the sintered compacts. Although grain coarsening should occur during the HIP, $\mathrm{d}_{\mathrm{A}}$ still shows some correlation with milling time. Namely, $d_{A}$ logarithmically decreases with the increase of milling time. Moreover, it is worth emphasizing that $d_{A}^{-1 / 2}$ increases linearly as the milling time increase. Therefore, it may be concluded that the desirable harmonic structured SUS316L stainless steel can be acquired by controlling milling time.

Mechanical milling is a well-known method for producing UFG or NG materials. In the previous study [27], the average grain size of shell was approximately $2 \mu \mathrm{m}$ in the harmonic structured austenitic stainless steels produced by the planetary ball mill. Even the milling speed and time were attempted to be increased, the shell grain size was difficult to be lower than $1 \mu \mathrm{m}$. By contrast, much higher energy can be provided by the horizontal ball mill, which induces finer grain size in the present study.

\subsection{Improvement of mechanical properties in the harmonic structured SUS316L compacts}

The summarized tensile results of SUS316L stainless steels subjected to different types of processing are shown in Figure 6 and Table 2. Figure 6 shows the nominal strain- nominal stress curves of the specimens with different grain structures. As usual, the CG SUS316L bulk has good ductility but the strength is relatively low. The homogeneous UFG or NG SUS316L steels produced by cold rolling, SMAT [1] or thermal cycling [48-50,] always show extremely high strength (yield strength is over than 1000MPa), but the uniform elongation is inferior (uniform 
elongation is lower than $2 \%$ ). By contrast, it is noteworthy that the yield strength and ultimate tensile strength of the harmonic structured SUS316L compacts are much higher than those of the CG bulk. Furthermore, the harmonic structured SUS316L compacts also show higher strain hardening capability and larger uniform elongation compared to those of the homogeneous UFG or NG steels. Severe plastic deformation (SPD) followed by appropriate thermal annealing can be used to synthesize the bimodal structured SUS316L stainless steels. Even compared with the heterogeneous bimodal structured SUS316L steels produced by a combination of ECAP and annealing [51], the harmonic structured SUS316L steel still show a superior balance of high strength and high ductility.

The strain energy density (SED) of the sintered compacts is shown in Fig.7. The SED of IP compact is approximately $307 \mathrm{~J} / \mathrm{cm}^{3}$. As the milling time increasing, the SED of the sintered compacts prepared from milled powders decreases gradually. The SED of MM180ks compact is only $70 \mathrm{~J} / \mathrm{cm}^{3}$. The decreased SED indicates that the ductility of the SUS316L compacts prepared from milled powders decreases as milling time increasing.

Figure 8 shows comparison between the yield strength and uniform elongation of the SUS316L stainless steels having various microstructures. Although the IP compact has partially network ultrafine-grained structure, improved balance of strength and ductility can be achieved. Moreover, the harmonic structured SUS316L compact prepared from MM108ks powders shows a superior combination of high strength and improved uniform elongation $\left(\sigma_{\mathrm{y}}=695 \mathrm{MPa}, \varepsilon_{\mathrm{u}}=27.1 \%\right)$.

Compared to the homogeneous UFG SUS316L steel produced by thermal cycling [50] with an average grain size of approximately $3 \mu \mathrm{m}$, the harmonic structured compact show slightly inferior ductility, but nearly one time higher yield strength. By contrast, compared to the SUS316L steel 
with a homogeneous grain size of approximately $1.4 \mu \mathrm{m}$, the harmonic structured steel has similar yield strength, but nearly one time larger uniform elongation. Compared with the heterogeneous bimodal structured SUS316L steels having similar CG size (approximately 1.0 $\mu \mathrm{m}$ ) and CG volume fraction (approximately 40\%) [51], the harmonic structured SUS316L steel (MM108ks) shows higher yield strength and larger uniform elongation. It is well-known that the inferior ductility of UFG or NG materials is caused by the early appearance of plastic strain instability [6-8, 16]. The difference of mechanical properties between harmonic structured stainless steel and heterogeneous bimodal structured one have been also studied [28]. It was found that both strength and ductility can be simultaneously increased in the harmonic structured steels. Moreover, the harmonic structure can thwarts the localization of plastic flow during mechanical loading. According to the simulation of tensile deformation behavior of the harmonic structured stainless steels, it is worth emphasizing that not only core can promote strain hardening capability, but also the peculiar network shell induces uniform distribution of strain during plastic deformation [29]. Therefore, the great balance of high strength and large uniform elongation can be achieved in harmonic structured SUS316L compacts.

\subsection{Appropriate harmonic structure design for the austenitic stainless steels}

It is well-known that the mechanical properties, i.e. hardness, strength and ductility, are related to grain size of metals [6-8]. Figure 9 shows the relationship between average grain size and mechanical properties. It can be observed that both hardness and yield strength increase linearly

with the increase of $d_{A}^{-1 / 2}$. It has been reported that the yield strength resembled the Hall-Petch relationship in the homogeneous grain-structured SUS316L steels [1, 14]. Although the harmonic 
structured SUS316L compacts have a bimodal grain size distribution, both hardness and yield strength still well resembles the Hall-Petch relationship.

In order to acquire the appropriate harmonic structure design, i.e. grain size and volume fraction of CG and UFG, for austenitic stainless steel. The effects of core grain size and shell fraction on the mechanical properties of the harmonic structured SUS316L compacts are discussed in Fig. 10 and Fig. 11, respectively. Because the variation of the shell grain size is not significant in the harmonic structured SUS316L compacts, so only the effect of core grain size on the mechanical properties is discussed here. It can be noted from Fig. 10a that both yield strength and ultimate tensile strength increase with the decrease of $d_{\text {core }}$, but the tendency of increment is different. Namely, the yield strength tends to close to ultimate tensile strength as $d_{\text {core }}$ decreases to approximately $1.2 \mu \mathrm{m}$. As well as strength, uniform elongation and total elongation also demonstrate different monotonic behavior (see Fig. 10b). It is noteworthy that the uniform elongation decreases slightly as $\mathrm{d}_{\text {core }}$ decreases to $1.2 \mu \mathrm{m}$. A similar tendency has also been observed in a bimodal structured ferrite solid solution by Hono et al. [42]. Figure 11 presents the relationship between shell fraction and mechanical properties of the harmonic structured SUS316L compacts. The total elongation decreases monotonically from approximately $50 \%$ to $28 \%$ as the shell fraction increases to approximately 55\%, while the uniform elongation decreases slightly. However, the decline of uniform elongation and total elongation is obvious as the shell fraction is more than $70 \%$. Namely, the strength can be increased as the volume fraction of ultrafine grains continues to increase, but the balance of high strength and high ductility tends to be deteriorated.

Therefore, it is suggested that for the harmonic structure designed austenitic stainless steel, the core grain size of approximately $1.2 \mu \mathrm{m}$ and shell volume fraction of approximately 50\%-60\% are 
the optimized microstructure characteristics.

\section{Conclusions}

In summary, the harmonic structure designed SUS316L compacts were produced by the combination of horizontal ball milling and hot isostatic pressing. Microstructure evolution and mechanical properties of the harmonic structured SUS316L stainless steels were analyzed. The following conclusions can be obtained:

(1) Owing to the wide distribution of initial powder size, partially harmonic structure can be formed in the sintered compact without mechanical milling. The harmonic structure designed SUS316L compacts can be acquired by high energy ball milling and subsequent powders consolidation. The desirable microstructure can be controlled by adjusting milling parameters.

(2) A great combination of high strength and improved uniform elongation $\left(\sigma_{y}=695 \mathrm{MPa}\right.$, $\left.\varepsilon_{\mathrm{u}}=27.1 \%\right)$ can be achieved in the harmonic structured SUS316L compact. The improved ductility was attributed to both the strain hardening induced by the coarse-grained structure and the extra strain hardening caused by the peculiar macroscopic network of ultrafine-grained structure.

(3) Although the harmonic structured SUS316L compacts have a bimodal grain size distribution, both hardness and yield strength still well resembles the Hall-Petch relationship.

(4) The core grain size of approximately $1.2 \mu \mathrm{m}$ and the shell volume fraction of approximately $50 \%-60 \%$ are recommended to be the optimized harmonic structure design for austenite stainless steel. 


\section{Acknowledgment}

This research was supported by the Japan Science and Technology Agency (JST) under Collaborative Research Based on Industrial Demand "Heterogeneous Structure Control: Towards Innovative Development of Metallic Structural Materials", and by the National Natural Science Foundation of China (No. 51435012, 11562015).

\section{References}

[1] X.H. Chen, J. Lu, L. Lu, K. Lu, Tensile properties of a nanocrystalline 316L austenitic stainless steel. Scr. Mater. 52 (2005) 1039-1044.

[2] H.W. Huang, Z.B. Wang, J. Lu, K. Lu, Fatigue behaviors of AISI 316L stainless steel with a gradient nanostructured surface layer. Acta Mater. 87 (2015) 150-160.

[3] W. Pachla, J. Skiba, M. Kulczyk, S. Przybysz, M. Przybysz, M. Wróblewska, R. Diduszko, R. Stępniak, J. Bajorek, M. Radomski, W. Fąfara, Nanostructurization of 316L type austenitic stainless steels by hydrostatic extrusion. Mater. Sci. Eng. A 615(2014)116-127.

[4] M. Song, K. Guan, W. Qin, J. Szpunar, J. Chen, Size effect criteria on the small punch test for AISI 316L austenitic stainless steel. Mater. Sci. Eng. A 606 (2014) 346-353.

[5] P. La, F. Wei, X. Lu, C. Chu, Y. Wei, H. Wang, Effect of annealing temperature on microstructure and mechanical properties of bulk $316 \mathrm{~L}$ stainless steel with nano-and micro-crystalline dual phases. Metall. Mater. Trans. A 45 (2014) 5236-5244.

[6] M.A. Meyers, A.Mishra, D.J. Benson, Mechanical properties of nanocrystalline materials. Prog. Mater. Sci. 51 (2006) 427-556.

[7] R.Z. Valiev, M.J. Zehetbauer, Y. Estrin, H.W. Höppel, Y. Ivanisenko, H. Hahn, G. Wilde, H.J. 
Roven, X. Sauvage, T.G. Langdon, The innovation potential of bulk nanostructured materials. Adv. Eng. Mater. 9 (2007) 527-533.

[8] Y. Estrin, A. Vinogradov, Extreme grain refinement by severe plastic deformation: A wealth of challenging science. Acta Mater. 61 (2013) 782-817.

[9] R. Zheng, Y. Sun, K. Ameyama, C. Ma, Optimizing the strength and ductility of spark plasma sintered Al 2024 alloy by conventional thermo-mechanical treatment. Mater. Sci. Eng. A 590 (2014) $147-152$.

[10] R.Z. Valiev, Materials science: nanomaterial advantage. Nature 419 (2002) 887-889.

[11] H. Ueno, K. Kakihata, Y. Kaneko, S. Hashimoto, A. Vinogradov, Nanostructurization assisted by twinning during equal channel angular pressing of metastable 316L stainless steel. J. Mater. Sci. 46 (2011) 4276-4283.

[12] Y. Mine, Z. Horita, Y. Murakami, Effect of hydrogen on martensite formation in austenitic stainless steels in high-pressure torsion. Acta Mater. 57 (2009) 2993-3002.

[13] I. Ucok, T. Ando, N.J. Grant, Property enhancement in Type 316L stainless steel by spray forming. Mater. Sci. Eng. A 133 (1991) 284-287.

[14] B.P. Kashyap, K. Tangri, On the Hall-Petch relationship and substructureal evolution in type 316L stainless steel. Acta metal. mater., 43 (1995) 3971-3981.

[15] M. Eskandari, A. Najafizadeh, A. Kermanpur, Effect of strain-induced martensite on the formation of nanocrystalline 316L stainless steel after cold rolling and annealing. Mater. Sci. Eng. A 1519 (2009) 46-50.

[16] E. Ma, Eight routes to improve the tensile ductility of bulk nanostructured metals and alloys. JOM, 58 (2006) 49-53. 
[17] X. Guo, G. Yang, G.J. Weng, L.L. Zhu, Numerical simulation of ballistic performance of bimodal nanostructured metals. Mater. Sci. Eng. A 630 (2015) 13-26.

[18] X. Guo, G. Yang, G.J. Weng, The saturation state of strength and ductility of bimodal nanostructured metals. Mater. Lett. 175 (2016) 131-134.

[19] Z. Lee, V. Radmilovic, B. Ahn, E.J. Lavernia, S. Nutt, Tensile deformation and fracture mechanism of bulk bimodal ultrafine-grained Al-Mg alloy. Metall. Mater. Trans. A 41A (2010) 795-801.

[20] N. Tsuji, N. Kamikawa, R. Ueji, N. Takata, H. Koyama, D. Terada, Managing both strength and ductility in ultrafine grained steels. ISIJ Int. 48 (2008) 1114-1121.

[21] G. Dirras, J. Gubicza, S. Ramtani, Q. Bui and T. Szilágyi, Microstructure and mechanical characteristics of bulk polycrystalline Ni consolidated from blends of powders with different particle size. Mater. Sci. Eng. A 527 (2010) 1206-1214.

[22] R. Zheng, Y. Sun, W. Xiao, K. Ameyama, C. Ma, Nanostructured Al87Ni8.5Ce3Fe1Cu0.5 alloy prepared by mechanical milling spark plasma sintering and hot extrusion. Mater. Sci. Eng. A 606 (2014) 426-433.

[23] T. H. Fang, W. L. Li, N. R. Tao, K. Lu, Revealing extraordinary intrinsic tensile plasticity in gradient nano-grained copper. Science 331 (2011) 1587.

[24] K. Lu, Making strong nanomaterials ductile with gradients. Science 345 (2014) 1455.

[25] L. Jiang, K. Ma, H. Yang, M. Li, E. J. Lavernia, J.M. Schoenung, The microstructural design of trimodal aluminum composites. JOM 66(2014) 898-908.

[26] K. Ameyama, H. Fujiwara, Creation of Harmonic Structure Materials with Outstanding Mechanical Properties. Mater. Sci. Forum 706-709 (2012) 9-16. 
[27] Z. Zhang, S.K. Vajpai, D. Orlov, K. Ameyama, Improvement of mechanical properties in SUS304L steel through the control of bimodal microstructure characteristics. Mater. Sci. Eng. A 598 (2014) 106-113.

[28] Z. Zhang, D. Orlov, S.K. Vajpai, B. Tong, K. Ameyama, Importance of bimodal structure topology in the control of mechanical properties of a stainless steel. Adv. Eng. Mater. 17 (2015) 791-795.

[29] H. Yu, I. Watanabe, K. Ameyama, Deformation behavior analysis of harmonic structure materials by multi-scale finite element analysis. Adv. Mater. Res. 1088 (2015) 853-857.

[30] H. Fujiwara, H. Tanaka, M. Nakatani, K. Ameyama, Effects of nano/meso harmonic microstructure on mechanical properties in austenitic stainless steel produced by MM/HRS process. Mater. Sci. Forum 638-642 (2010) 1790-1795.

[31] O.P. Ciuca, M. Ota, S. Deng, K. Ameyama, Harmonic structure design of a SUS329J1 two phase stainless steel and its mechanical properties. Mater. Trans. 54 (2013) 1629-1633.

[32] M. Ota, S.K. Vajpai, R. Imao, K. Kurokawa, K. Ameyama, Application of high pressure gas jet mill process to fabricate high performance pure titanium. Mater. Trans. 56 (2015) 154-159.

[33] T. Sekiguchi, K. Ono, H. Fujiwara, K. Ameyama, New microstructure design for commercially pure titanium with outstanding mechanical properties by mechanical milling and hot roll sintering. Mater. Trans. 51 (2010) 39-45.

[34] H. Fujiwara, T. Sekiguchi, K. Ameyama, Mechanical properties of pure titanium and Ti-6Al-4V alloys with a new tailored nano/meso hybrid microstructure. Int J. Mater. Res. 100 (2009) 796-799.

[35] S.K. Vajpai, M. Ota, T. Watanabe, R. Maeda, T. Sekiguchi, T. Kusaka, K. Ameyama, The 
development of high performance Ti-6Al-4V alloy via a unique microstructural design with bimodal grain size distribution. Metall. Mater. Trans. A 46 (2015) 903-914.

[36] D. Orlov, H. Fujiwara, K. Ameyama, Obtaining copper with harmonic structure for the optimal balance of structure-performance relationship. Mater. Trans. 54 (2013) 1549-1553.

[37] C. Sawangrat, S. Kato, D. Orlov, K. Ameyama, Harmonic-structured copper: performance and proof of fabrication concept based on severe plastic deformation of powders. J. Mater. Sci. 49 (2014) 6579-6585.

[38] S.K. Vajpai, C. Sawangrat, O.Yamaguchi, O.P. Ciuca, K. Ameyama, Effect of bimodal harmonic structure design on the deformation behaviour and mechanical properties of Co-Cr-Mo alloy. Mater. Sci. Eng. C 58 (2016) 1008-1015.

[39] C. Sawangrat, O. Yamaguchi, S.K. Vajpai, K. Ameyama, Application of harmonic structure design to biomedical Co-Cr-Mo alloy for improved mechanical properties. Mater. Trans. 55 (2014) 99-105.

[40] B. Srinivasarao, K. Oh-ishi, T. Ohkubo, K. Hono, Bimodally grained high-strength Fe fabricated by mechanical alloying and spark plasma sintering. Acta Mater. 57 (2009) 3277-3286.

[41] T. Sasaki, T. Ohkubo, K. Hono, Microstructure and mechanical properties of bulk nanocrystalline Al-Fe alloy processed by mechanical alloying and spark plasma sintering. Acta Mater. 57 (2009) 3529-3538.

[42] K. Oh-ishi, H.W. Zhang, T. Ohkubo, K. Hono, Microstructure characterization of bulk nanocrystalline $\mathrm{Fe}-0.8 \mathrm{C}$ alloy produced by mechanical milling and spark plasma sintering. Mater. Sci. Eng. A 456 (2007) 20-27.

[43] B.O. Han, E.J. Lavernia, Z. Lee, S. Nutt, D. Witkin, Deformation behavior of bimodal 
nanostructured $5083 \mathrm{Al}$ alloys. Metall. Mater. Trans. A 36 (2005) 957-965.

[44] O. Ertorer, T. Topping, Y. Li, W. Moss, E.J. Lavernia, Enhanced tensile strength and high ductility in cryomilled commercially pure titanium. Scr. Mater. 60 (2009) 586-589.

[45] C. Suryanarayana, Mechanical alloying and milling. Prog. Mater. Sci. 46 (2001) 1-184.

[46] M. Zhao, F. Yin, T. Hanamura, K. Nagai, A. Atrens, Relationship between yield strength and grain size for a bimodal structural ultrafine-grained ferrite/cementite steel. Scr. Mater. 57 (2007) 857-860.

[47] H. Fujiwara, H. Inomoto, R. Sanada, K. Ameyama, Nano-ferrite formation and strain-induced-ferrite transformation in an SUS316L austenitic stainless steel. Scr. Mater. 44 (2001) 2039-2042.

[48] Y.M. Wang, K. Wang, D. Pan, K. Lu, K.J. Hemker, E. Ma, Microsample tensile testing of nanocrystalline copper. Scr. Mater. 48 (2003) 1581-1586.

[49] H. Ueno, K. Kakihata, Y. Kaneko, S. Hashimoto, A. Vinogradov, Enhanced fatigue properties of nanostructured austenitic SUS 316L stainless steel. Acta Mater. 59 (2011) 7060-7069.

[50] W. A. Poling, Grain size effects in micro-tensile testing of austenitic stainless steel. Colorado School of Mines, 2012.

[51] A. Vinogradov, I.S. Yasnikov, H. Matsuyama, M. Uchida, Y. Kaneko, Y. Estrin, Controlling strength and ductility: Dislocation-based model of necking instability and its verification for ultrafine grain 316L steel. Acta Mater. 106 (2016) 295-303. 


\section{Table Captions:}

Table 1 Chemical composition of commercial SUS316L gas-atomized powders (mass\%).

Table 2 Microstructural characteristics and mechanical properties of SUS316L stainless steels subjected to various preparation methods.

\section{Figure captions:}

Figure 1 The morphology of (a) Initial powders; (b) Powders milled for 36ks; (c) Powders milled for 108ks; (d) Powders milled for 180ks.

Figure 2 Microstructure of SUS316L stainless steels produced by different preparation methods: bulk (a and f), IP (b and g), MM36ks (c and h), MM108ks (d and i) and MM180ks (e and j). (a-e) are grain boundary maps. The blue lines indicate misorientations above $15^{\circ}$, and the green lines between 1 and $15^{\circ}$. (f-j) are grain size distribution maps. The aqua blue area indicates the grain is over than $1 \mu \mathrm{m}$, and the orange area is less than $1 \mu \mathrm{m}$.

Figure 3 The XRD results of (a) milled powders and (b) sintered compacts.

Figure 4 Effect of milling time on microstructural characteristics of the sintered SUS316L compacts: (a) Grain size; (b) UFG volume fraction.

Figure 5 Effect of mechanical milling time on average grain size of the sintered SUS316L 
compacts.

Figure 6 Tensile results of SUS316L stainless steel specimens having various microstructures.

Figure 7 The strain energy density (SED) of the sintered compacts.

Figure 8 Relationship between yield strength and uniform elongation of SUS316L stainless steels having various microstructures.

Figure 9 Diagram illustrating the dependence of mechanical prosperities of the sintered SUS316L compacts on the average grain size: (a) Vickers hardness; (b) Yield strength.

Figure 10 Relationship between mechanical properties and core grain size in the harmonic structured SUS316L compacts: (a) Strength vs $d_{\text {core }}$; (b) Elongation vs $d_{\text {core }}$.

Figure 11 Relationship between mechanical properties and shell fraction in the harmonic structured SUS316L compacts: (a) Strength vs $\mathrm{S}_{\mathrm{f}}$; (b) Elongation vs $\mathrm{S}_{\mathrm{f}}$. 

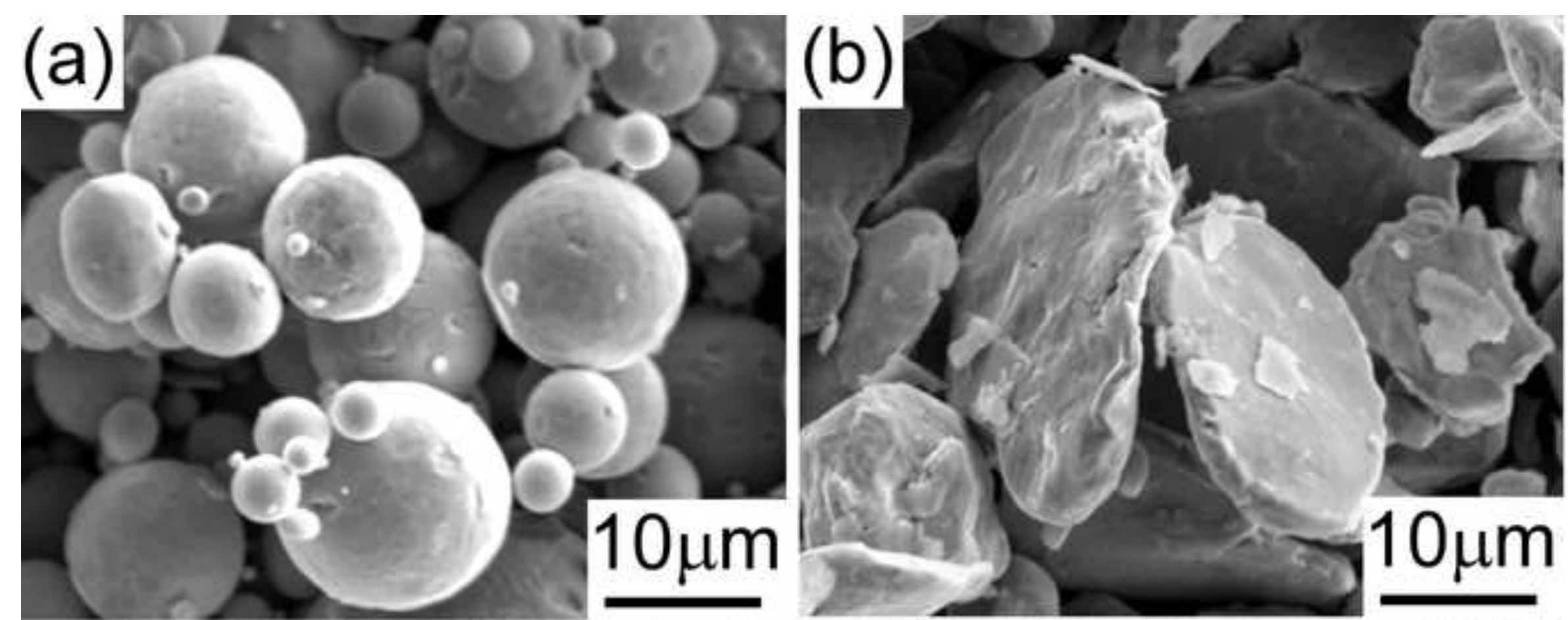

(c)

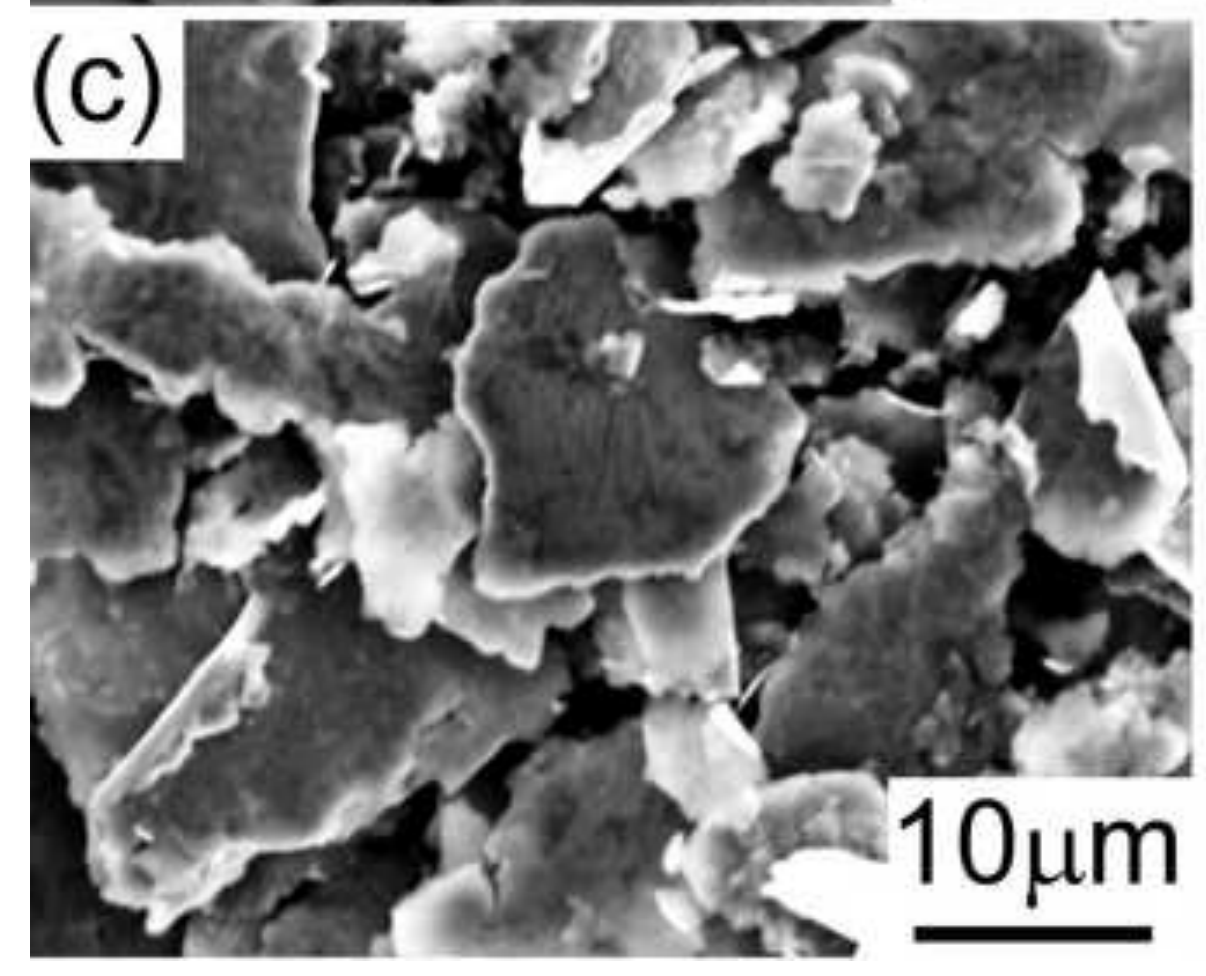

(d)

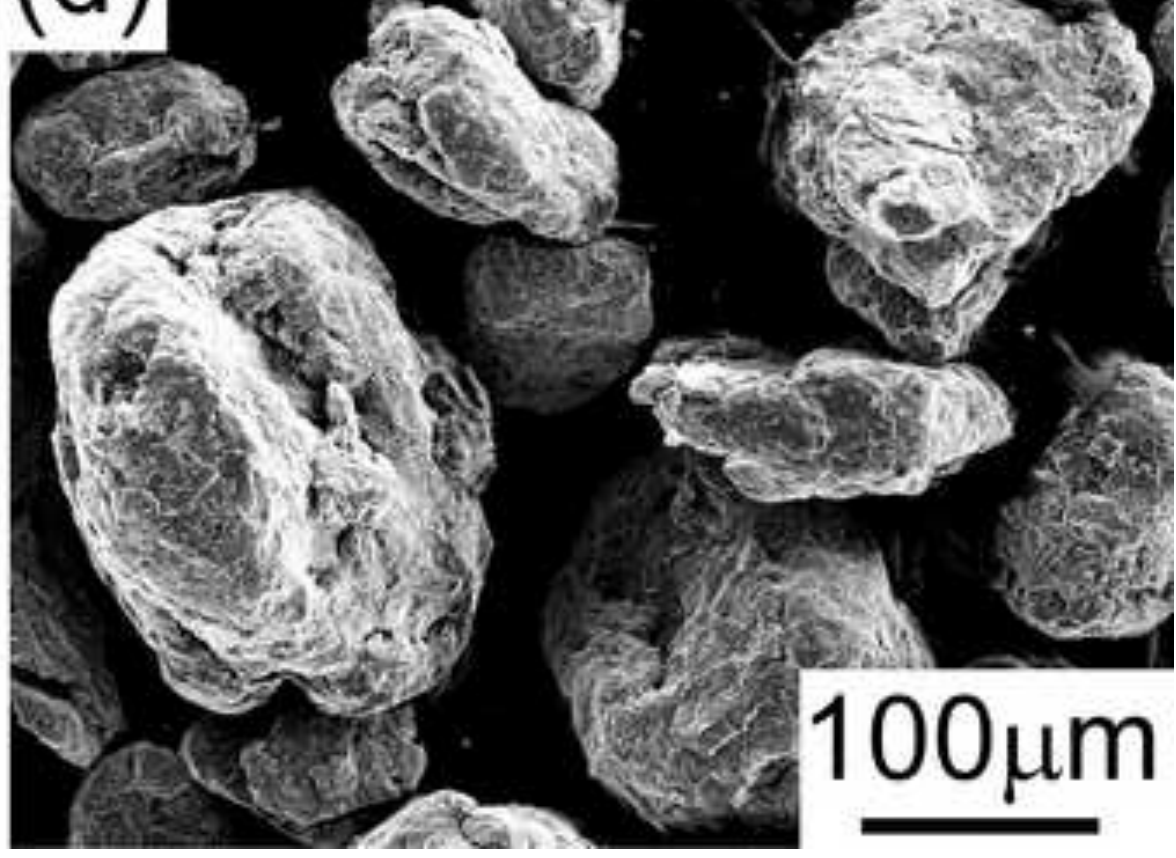



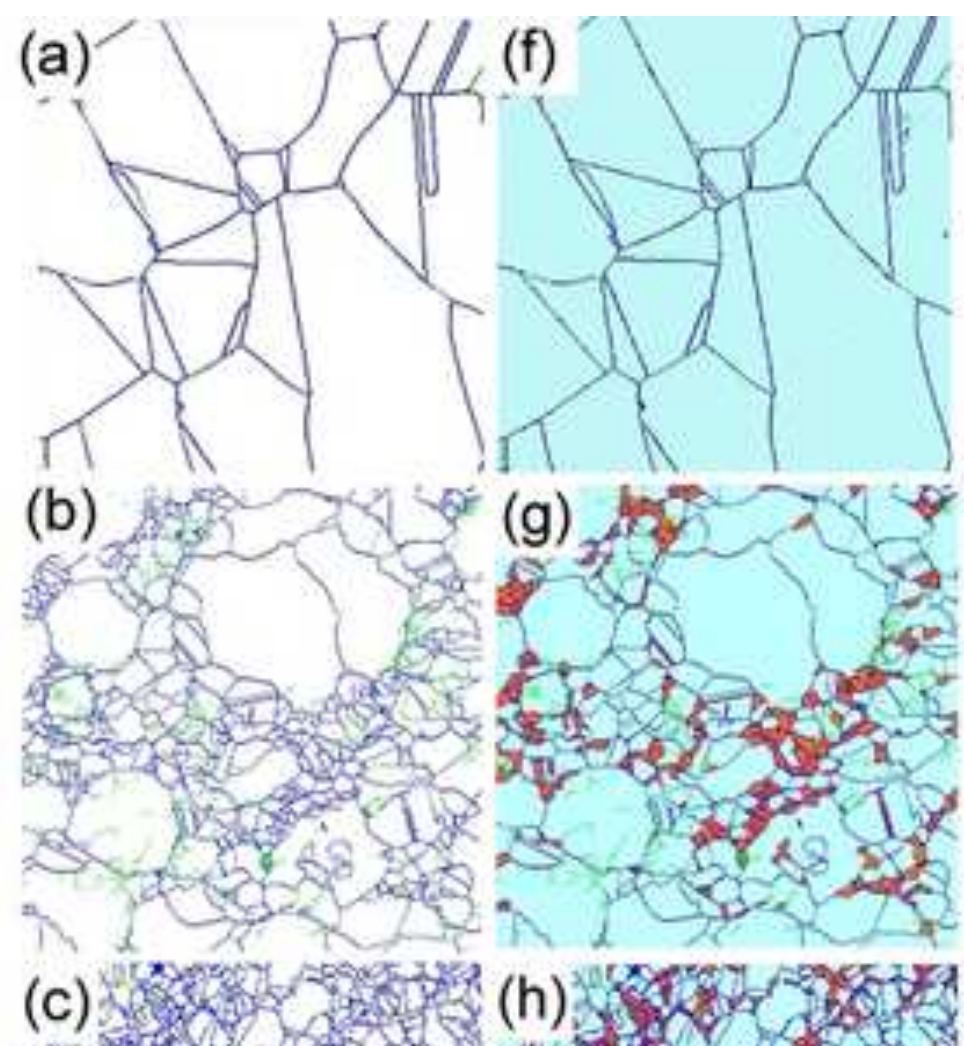

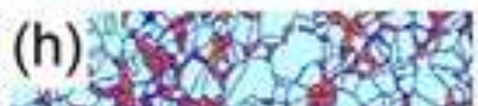

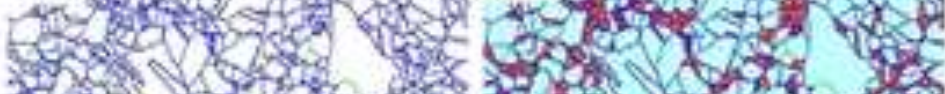

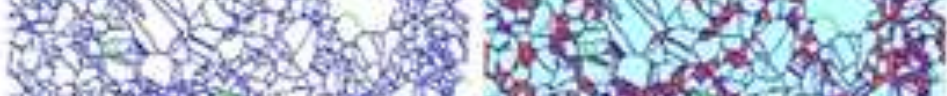

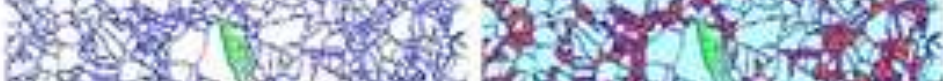

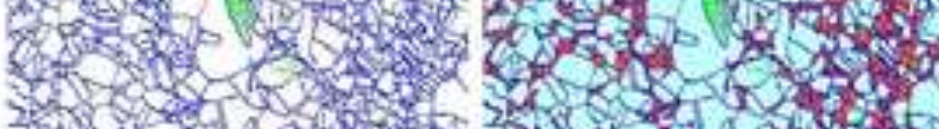

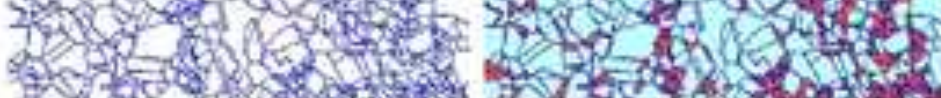

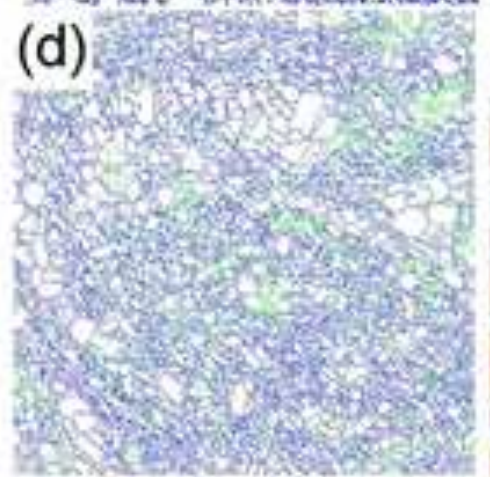

(e)
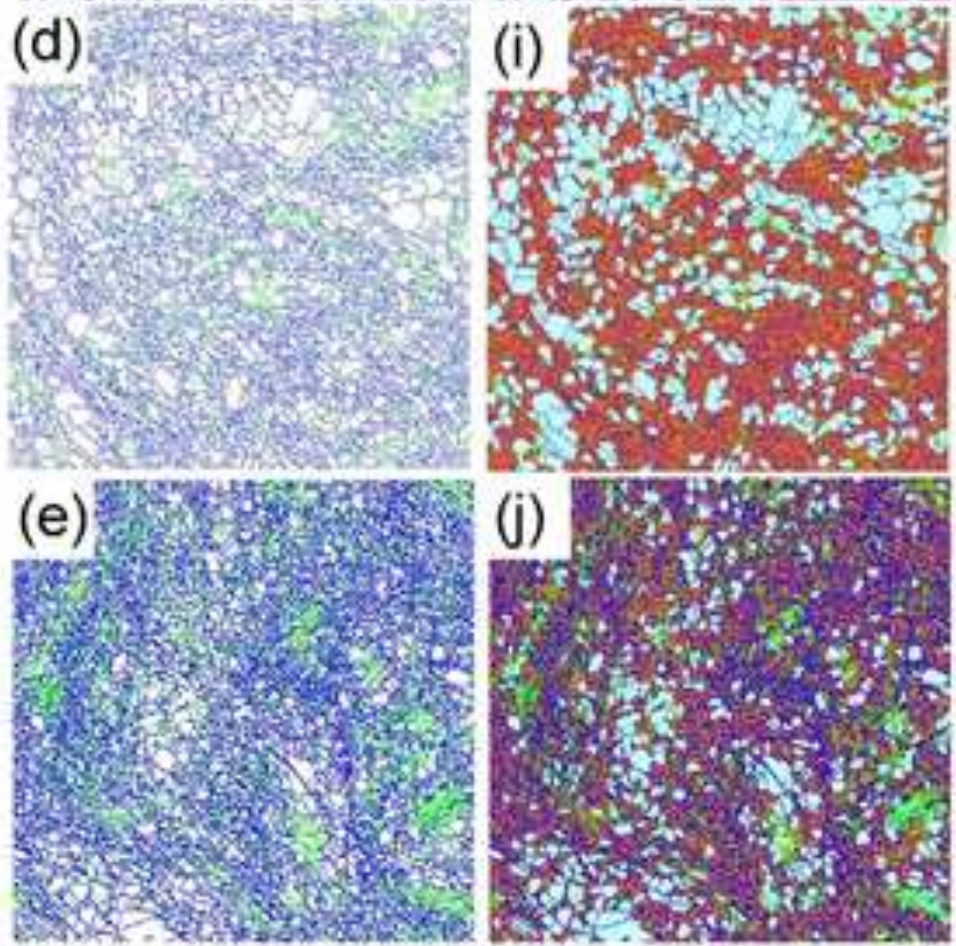

(j) 30 ors. $1 \%$

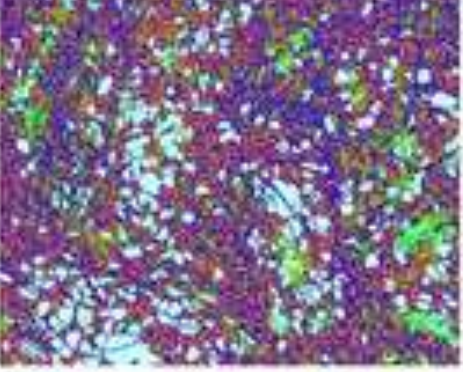



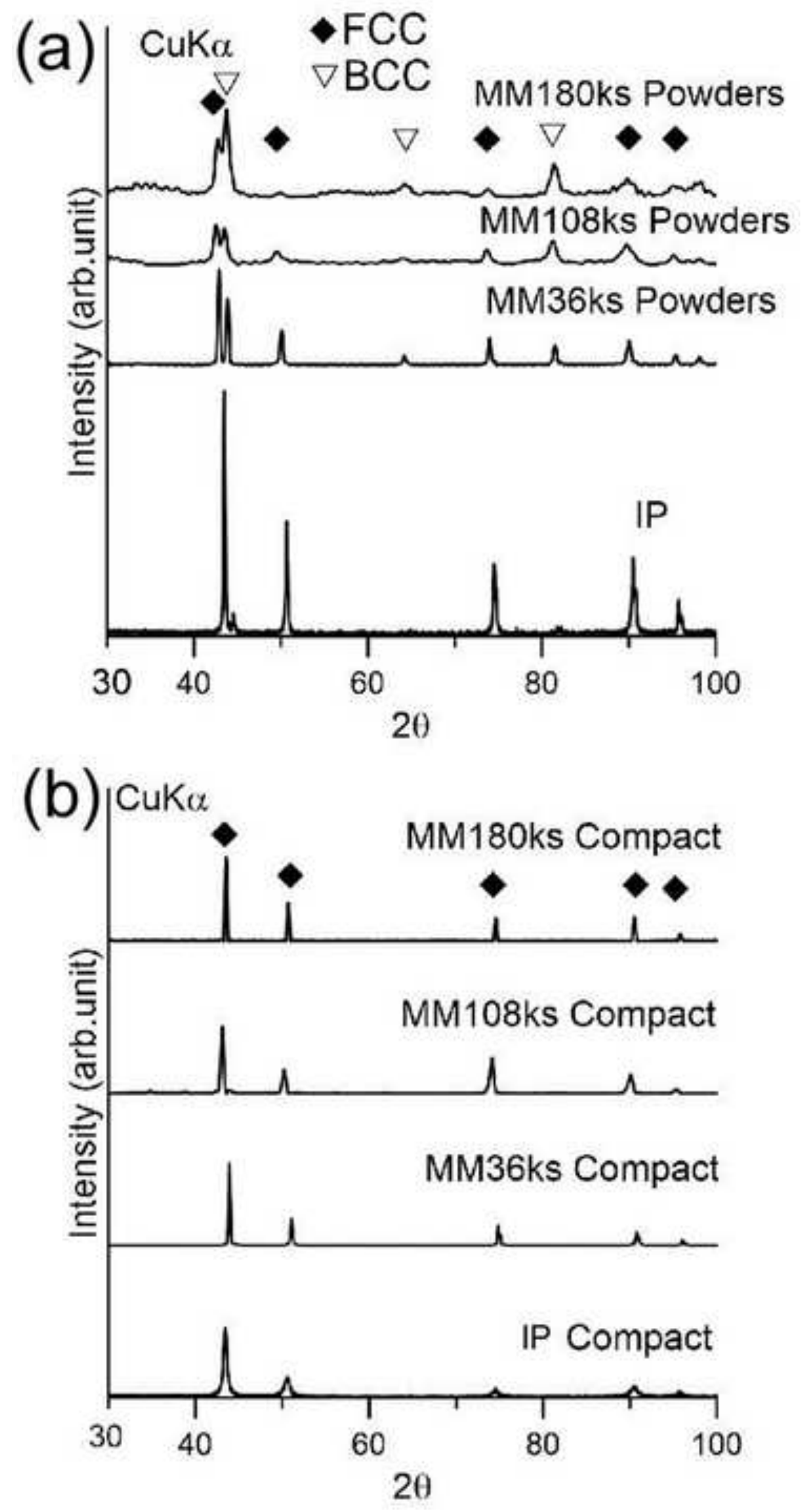

Figure 3 

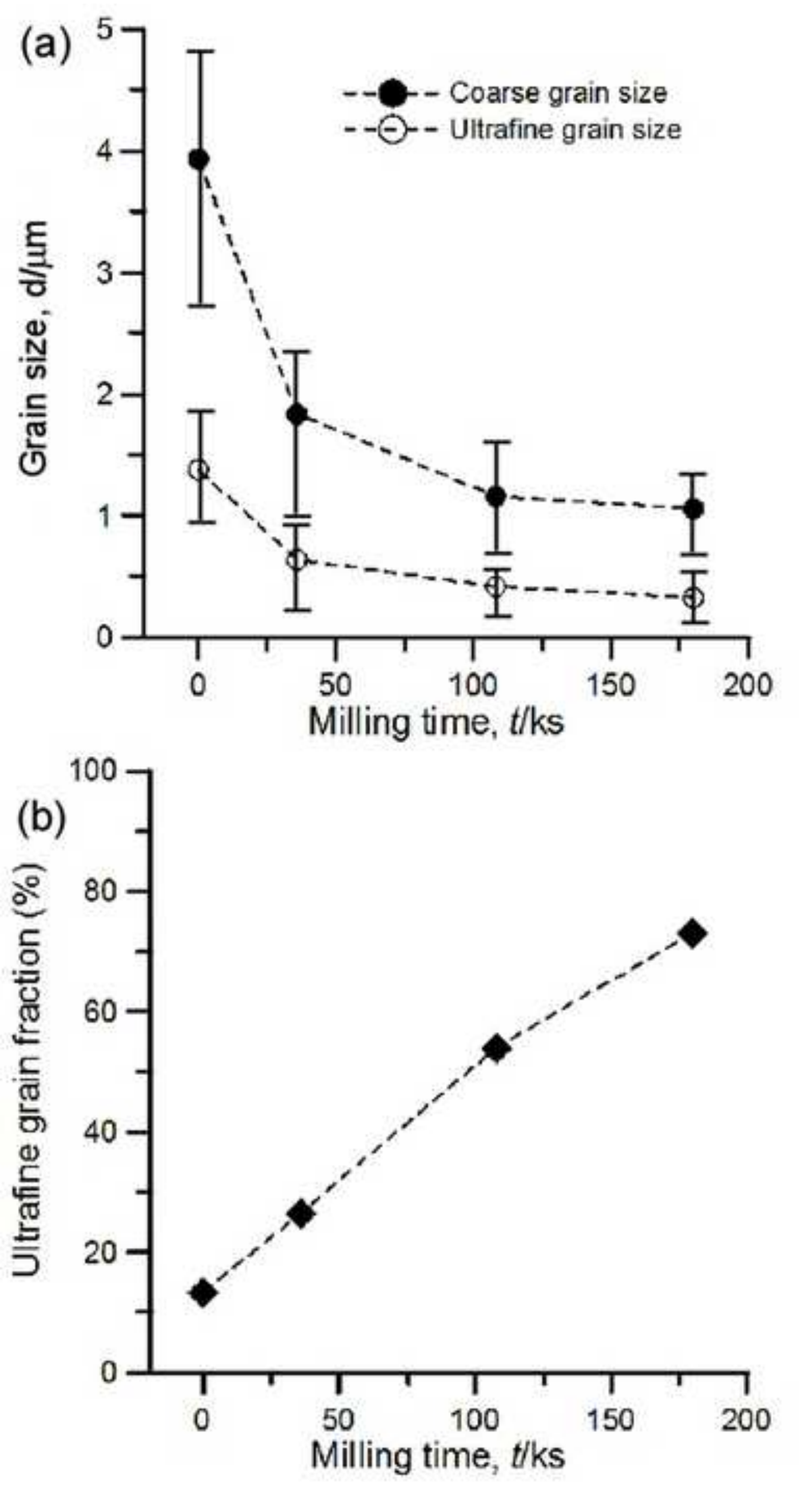

Figure 4

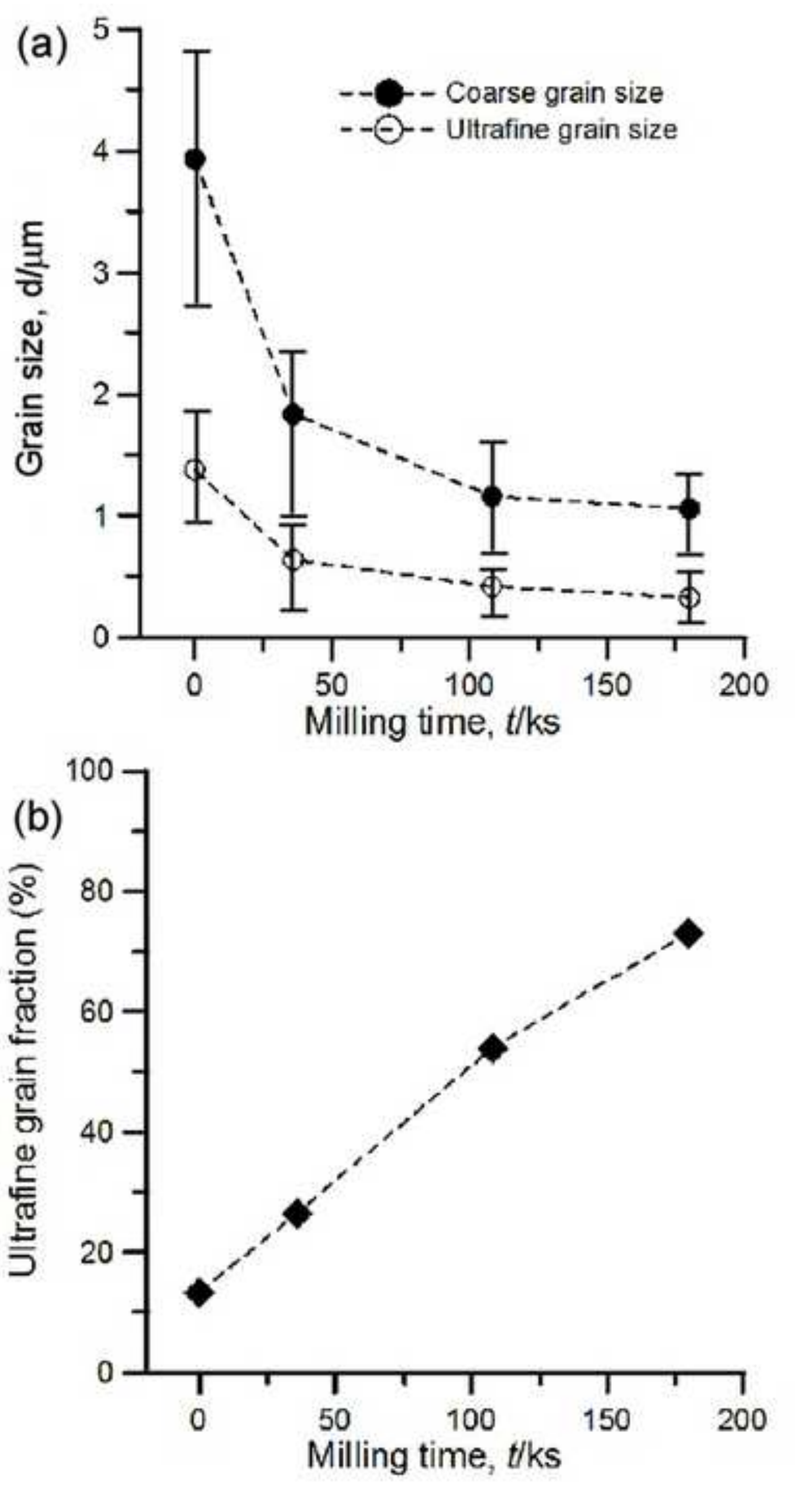

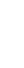
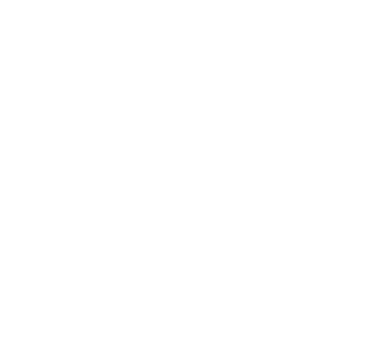


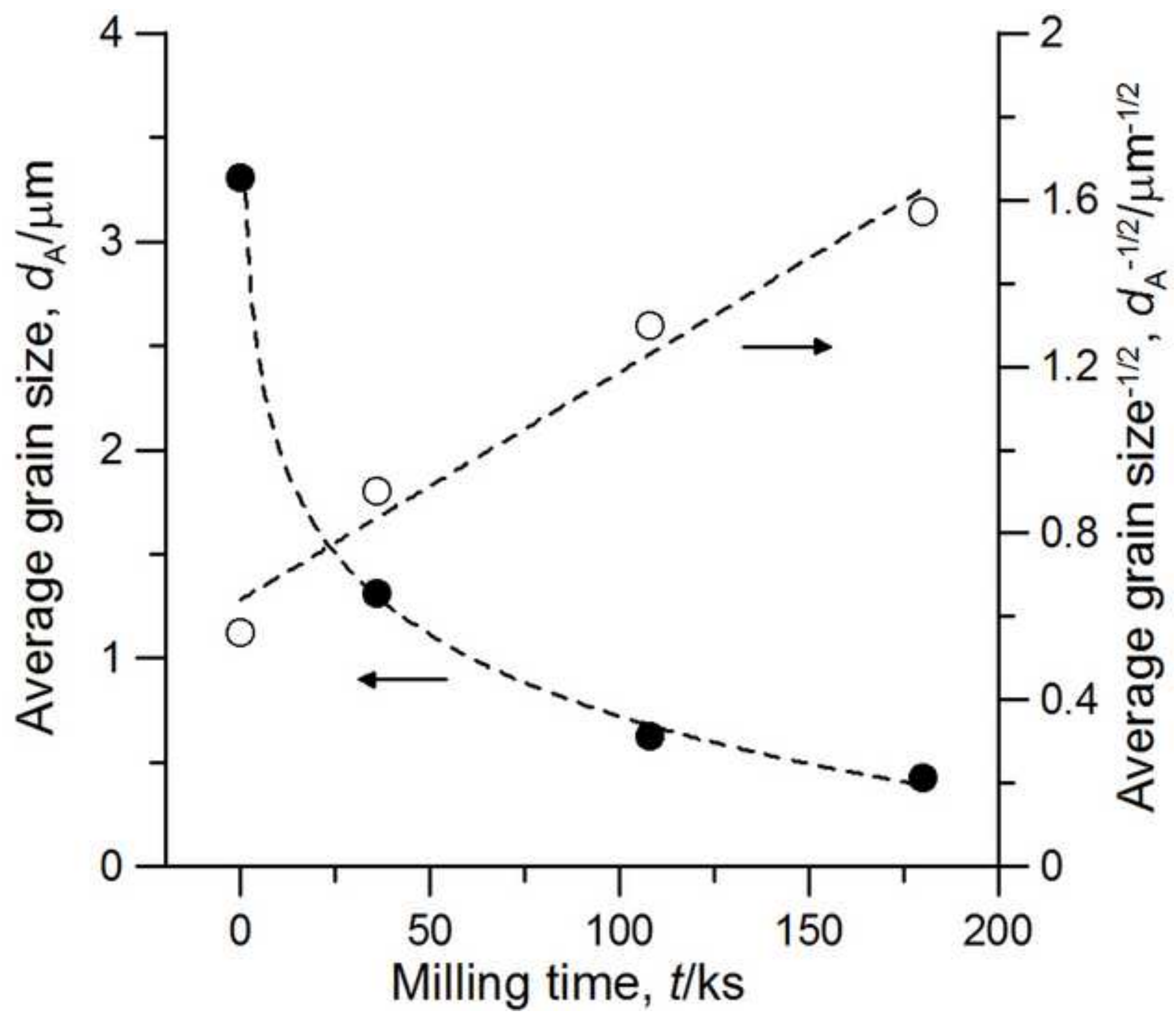




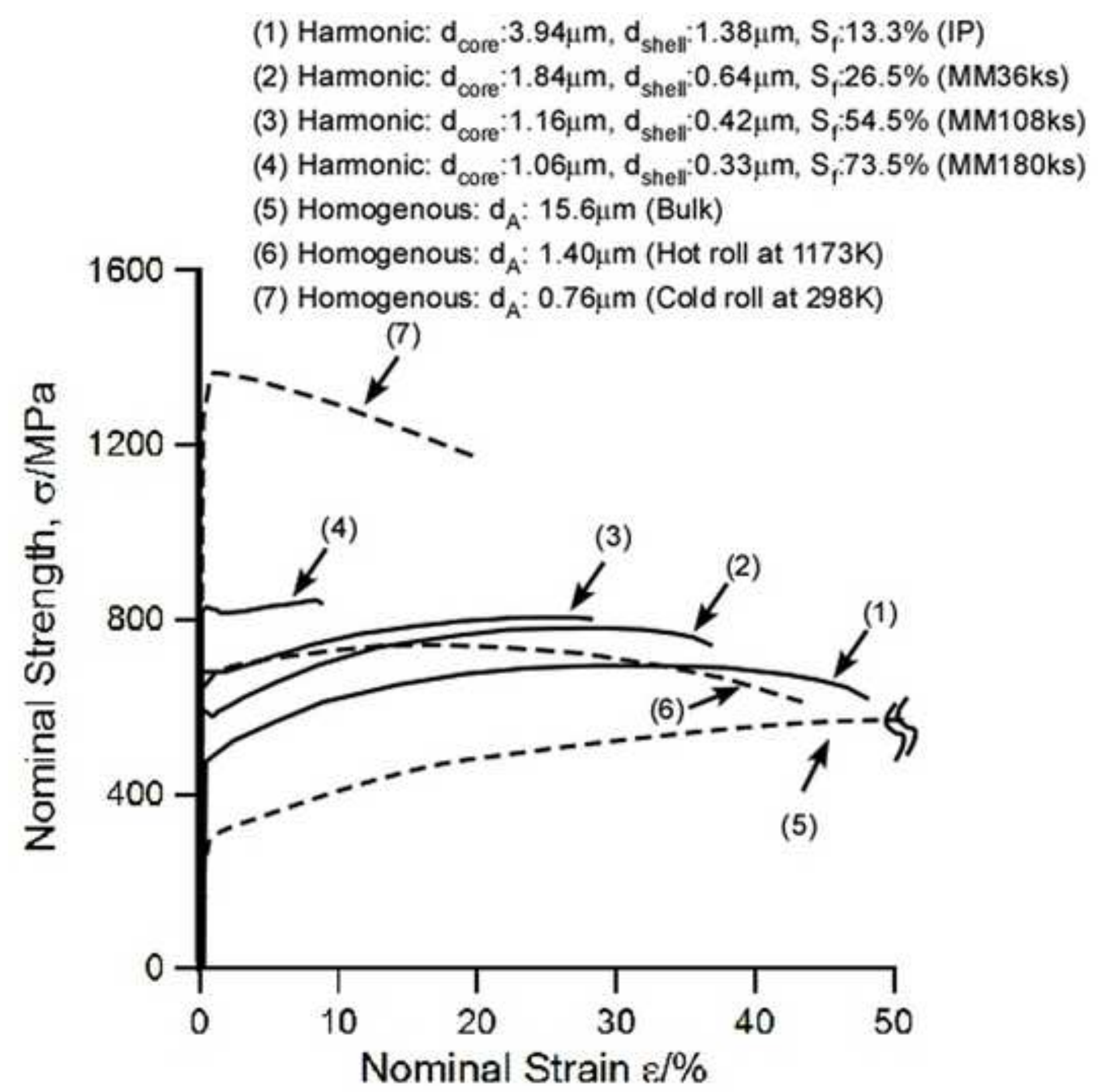




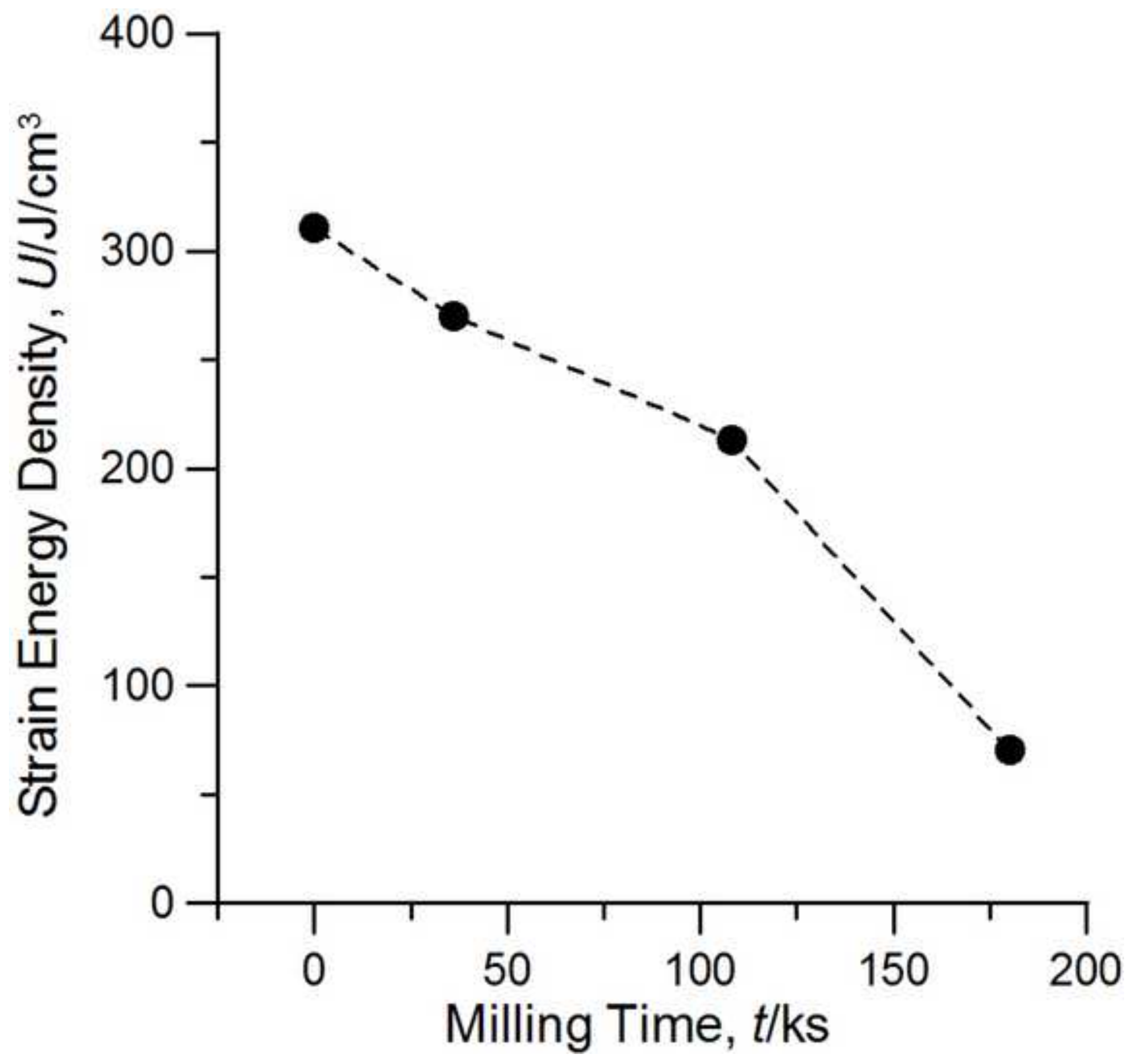




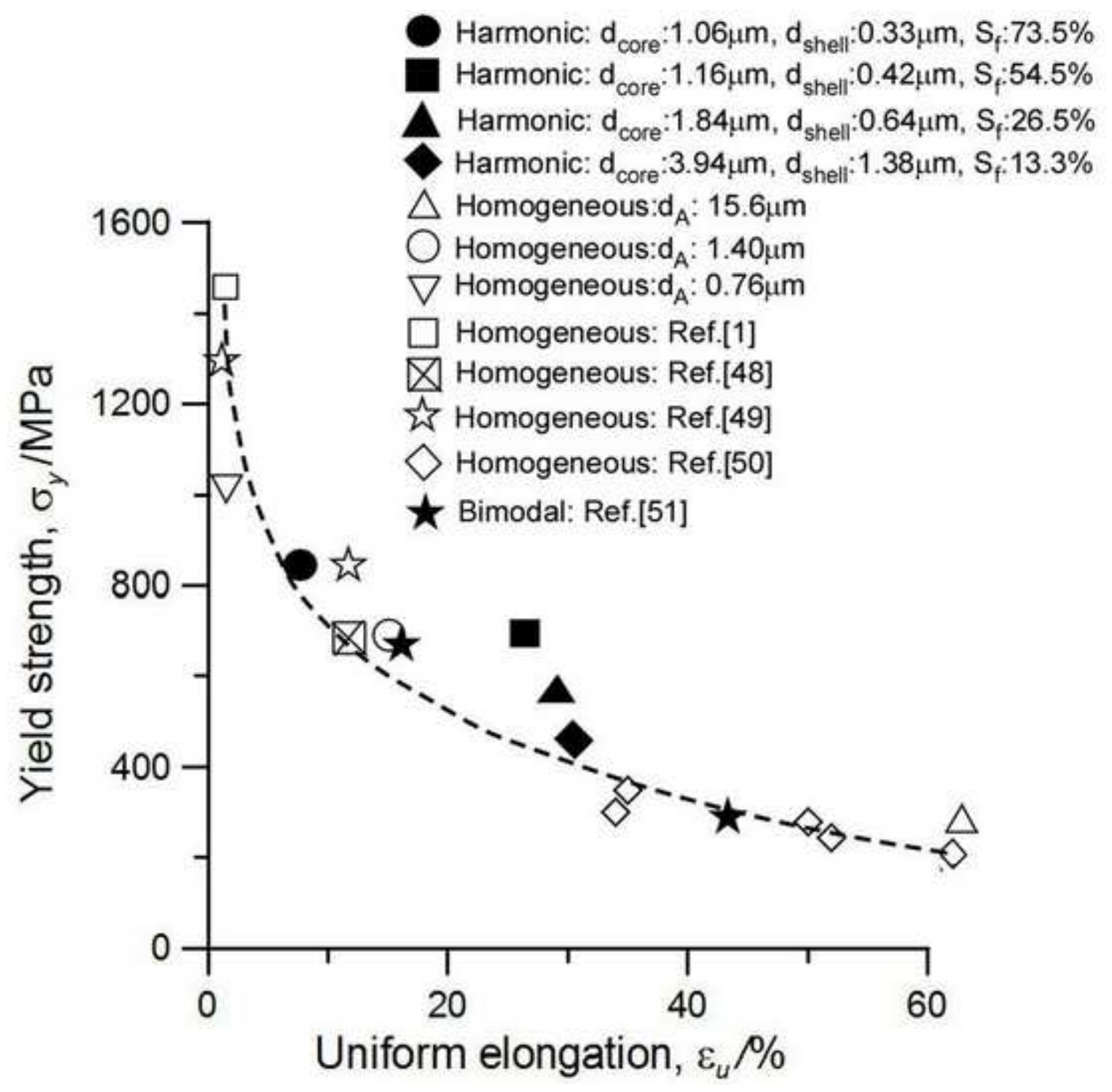




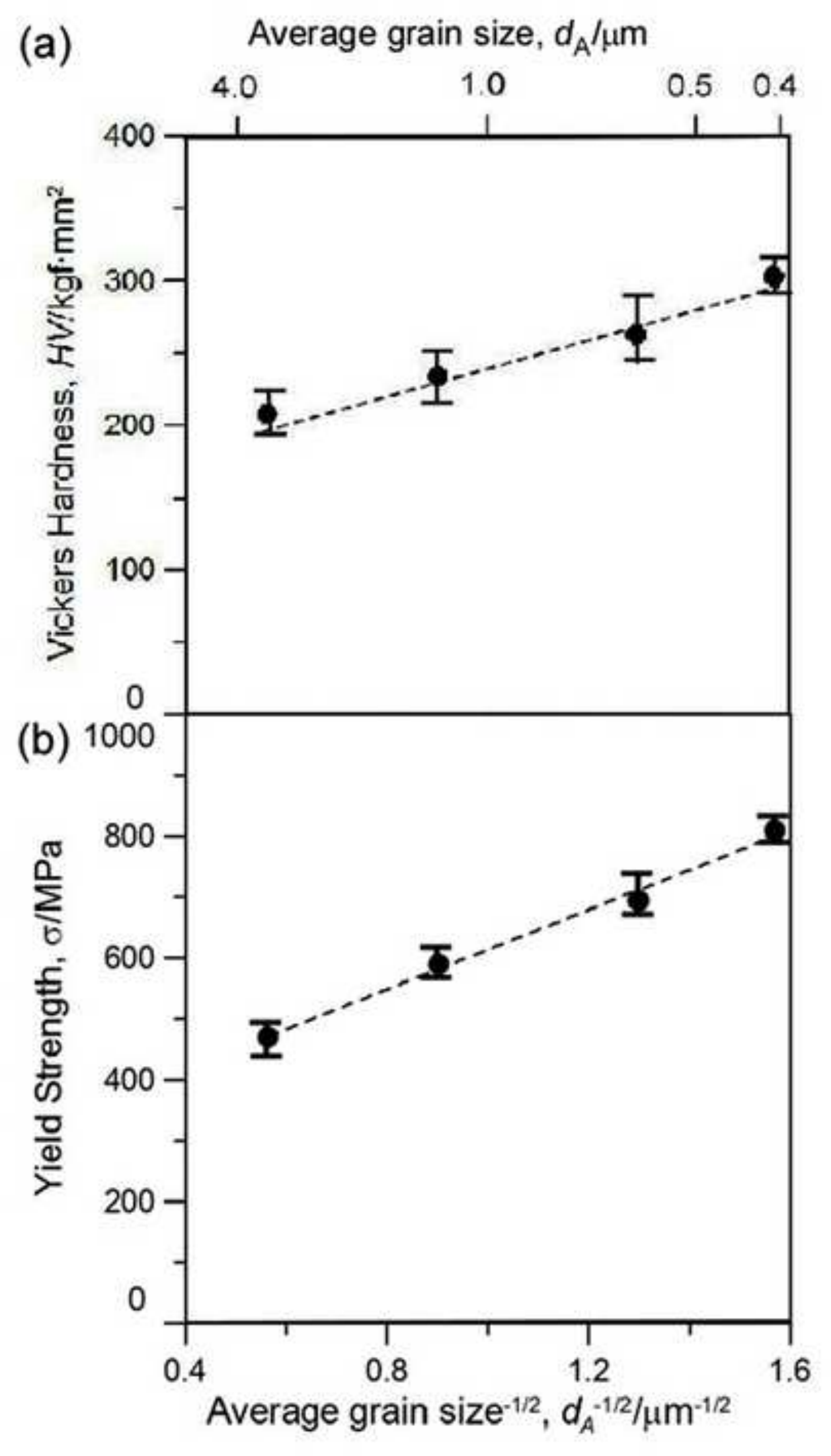

(a)

a) Average grain size, $d_{A} / \mu m$ . 


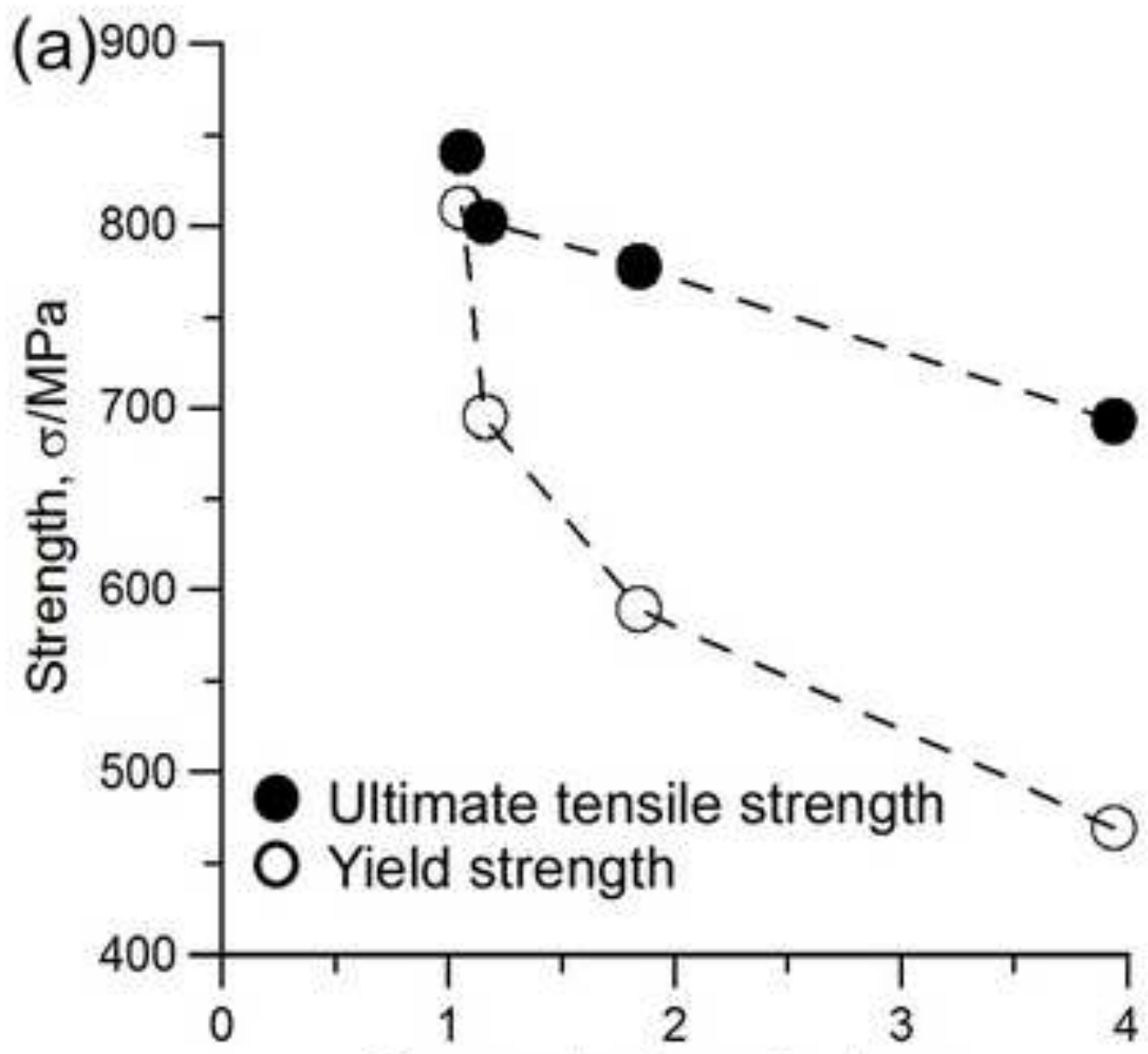

Core grain size, $d_{c o r e} / \mu \mathrm{m}$

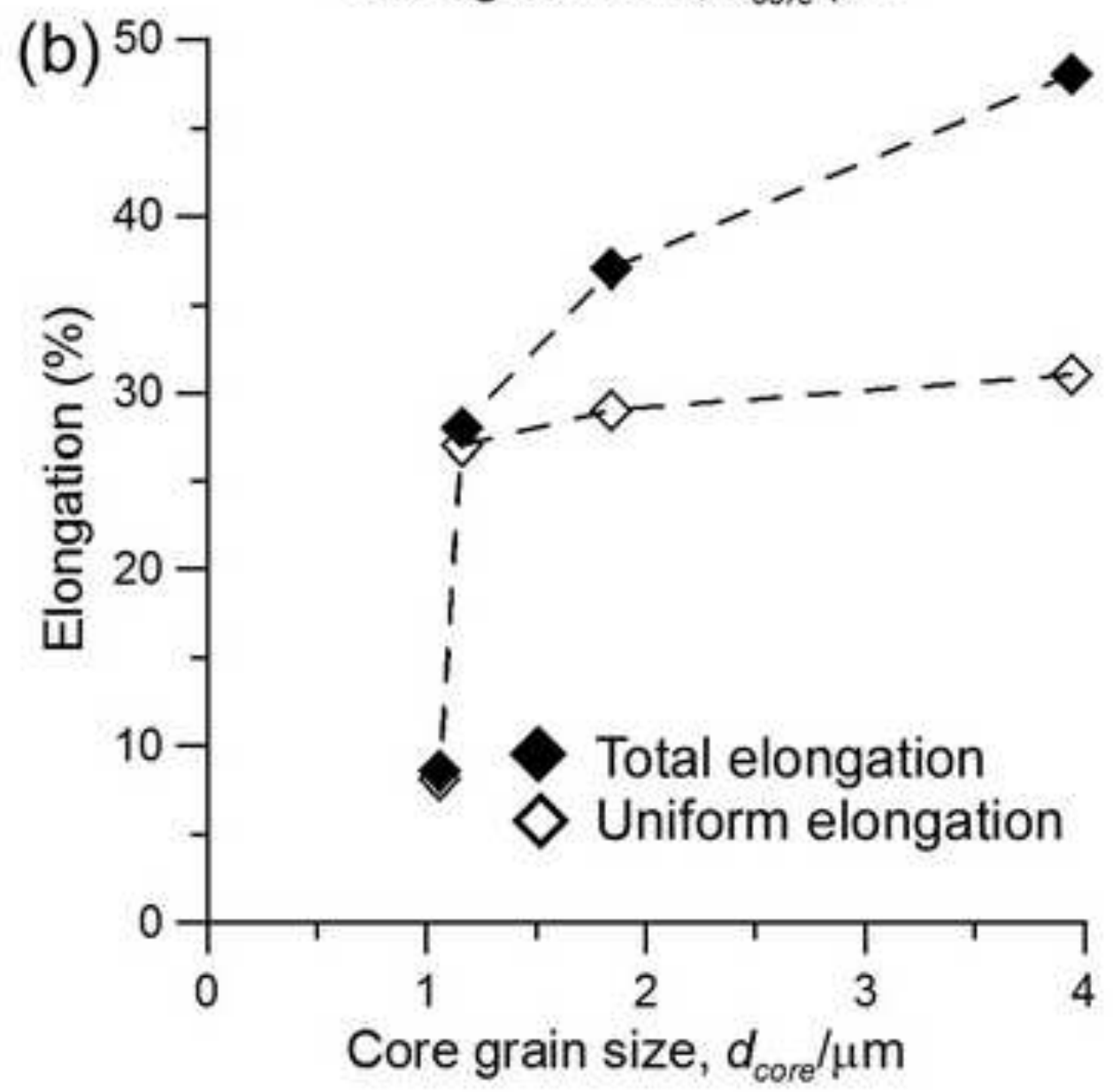



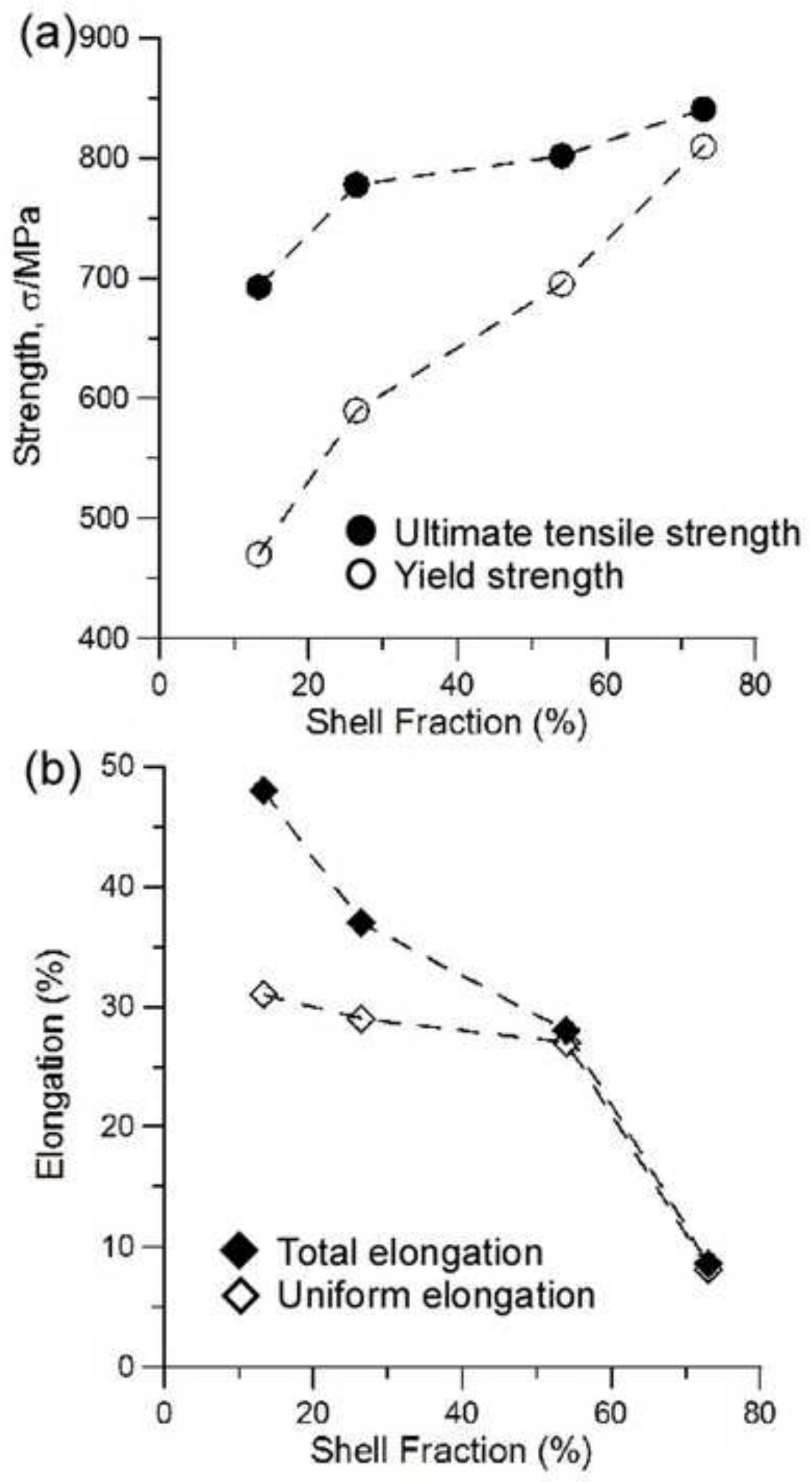
Table 1 Chemical composition of SUS316L gas-atomized powders (mass\%).

\begin{tabular}{ccccccccc}
\hline $\mathrm{C}$ & $\mathrm{Si}$ & $\mathrm{Mn}$ & $\mathrm{P}$ & $\mathrm{S}$ & $\mathrm{Ni}$ & $\mathrm{Cr}$ & $\mathrm{Mo}$ & $\mathrm{Fe}$ \\
\hline 0.018 & 0.9 & 1.07 & 0.032 & 0.017 & 12.44 & 17.31 & 2.11 & Bal. \\
\hline
\end{tabular}


Table 2 Microstructural characteristics and mechanical properties of SUS316L stainless steels subjected to various preparation methods.

\begin{tabular}{|c|c|c|c|c|c|c|c|c|}
\hline \multirow[t]{2}{*}{ No. } & \multirow[t]{2}{*}{ Processing** } & \multirow{2}{*}{$\begin{array}{c}\sigma_{\mathrm{y}}^{*} \\
{[\mathrm{MPa}]}\end{array}$} & \multirow{2}{*}{$\begin{array}{c}\sigma_{\mathrm{UTS}} * \\
{[\mathrm{MPa}]}\end{array}$} & \multirow{2}{*}{$\begin{array}{c}\varepsilon_{\mathrm{u}}^{*} \\
{[\%]}\end{array}$} & \multirow{2}{*}{$\begin{array}{c}\varepsilon_{\mathrm{t}}^{*} \\
{[\%]}\end{array}$} & \multicolumn{2}{|c|}{$\begin{array}{c}\text { Average grain size }[\mu \mathrm{m}], \\
\quad(\text { fraction } \%)\end{array}$} & \multirow[t]{2}{*}{ Ref. } \\
\hline & & & & & & bulk or CG & UFG & \\
\hline 1 & IP & 470 & 693 & 31.0 & 48.0 & $\begin{array}{c}3.94 \\
(86.7 \%)\end{array}$ & $\begin{array}{c}1.28 \\
(13.3 \%)\end{array}$ & Present \\
\hline 2 & MM36ks & 590 & 778 & 29.2 & 37.3 & $\begin{array}{c}1.84 \\
(73.5 \%)\end{array}$ & $\begin{array}{c}0.64 \\
(26.5 \%)\end{array}$ & Present \\
\hline 3 & MM108ks & 695 & 802 & 27.1 & 28.2 & $\begin{array}{c}1.16 \\
(45.5 \%)\end{array}$ & $\begin{array}{c}0.42 \\
(54.5 \%)\end{array}$ & Present \\
\hline 4 & MM180ks & 810 & 841 & 8.1 & 8.6 & $\begin{array}{c}1.06 \\
(26.5 \%)\end{array}$ & $\begin{array}{c}0.33 \\
(73.5 \%)\end{array}$ & Present \\
\hline 5 & Bulk & 315 & 585 & 66.8 & 87.7 & $\begin{array}{c}15.6 \\
(100 \%)\end{array}$ & --- & Present \\
\hline 6 & HR at $1173 \mathrm{~K}$ & 690 & 746 & 15.3 & 43.3 & $\begin{array}{c}1.40 \\
(100 \%)\end{array}$ & --- & Present \\
\hline 7 & CR at $298 \mathrm{~K}$ & 1024 & 1376 & 1.25 & 20.3 & $\begin{array}{c}0.76 \\
(100 \%)\end{array}$ & --- & Present \\
\hline 8 & SMAT & 1450 & 1550 & 1.0 & 3.4 & $\begin{array}{c}0.04 \\
(100 \%)\end{array}$ & --- & [1] \\
\hline 9 & $15 \% \mathrm{CR}$ at $77 \mathrm{~K}$ & 680 & 1050 & --- & 12 & --- & --- & {$[48]$} \\
\hline 10 & ECAP at $423 \mathrm{~K}-1$ pass & 850 & 900 & 15.0 & 30.0 & --- & --- & [49] \\
\hline 11 & ECAP at $423 \mathrm{~K}-3$ pass & 1300 & 1340 & 1.0 & 18.0 & $\begin{array}{c}0.01-0.04 \\
(100 \%)\end{array}$ & --- & [49] \\
\hline 12 & $\begin{array}{l}85 \% \mathrm{CR} \\
\mathrm{HT} \text { at } 1223 \mathrm{~K} / 3 \mathrm{~min}\end{array}$ & 350 & 680 & 35.0 & 45.0 & $\begin{array}{c}3.10 \\
(100 \%)\end{array}$ & --- & {$[50]$} \\
\hline 13 & $\begin{array}{l}\text { ECAP + } \\
\text { Annealing at } 973 \mathrm{~K}\end{array}$ & 640 & 880 & 18.0 & --- & $1.0(40 \%)$ & NT (60\%) & [51] \\
\hline 14 & $\begin{array}{l}\text { ECAP + } \\
\text { Annealing at } 1073 \mathrm{~K}\end{array}$ & 380 & 720 & 43.0 & --- & $\begin{array}{l}1.0-5.0 \\
(90 \%)\end{array}$ & NT (10\%) & [51] \\
\hline
\end{tabular}

${ }^{*} \sigma_{\mathrm{y}}-$ yield stress; $\sigma_{\mathrm{UTS}}-$ ultimate tensile stress; $\varepsilon_{\mathrm{u}}$-uniform elongation; $\varepsilon_{\mathrm{t}}-$-total elongation.

** MM-mechanical milling; IP-initial powder; HR-hot rolling; CR-cold rolling; SMAT -surface mechanical attrition treatment; HIP - hot isostatic pressing; ECAP - equal channel angular pressing; and HT-heat treatment; and NT-nano twins. 